Article

\title{
Does Access Trump Ownership? Exploring Consumer Acceptance of Access-Based Consumption in the Case of Smartphones
}

\author{
Flora Poppelaars ${ }^{1, *}$, Conny Bakker ${ }^{1}$ and Jo van Engelen ${ }^{1,2}$ \\ 1 Faculty of Industrial Design Engineering, Delft University of Technology, 2628 CE Delft, The Netherlands; \\ c.a.bakker@tudelft.nl (C.B.); j.m.l.vanengelen@tudelft.nl (J.v.E.) \\ 2 Faculty of Economics and Business, University of Groningen, 9747 AE Groningen, The Netherlands \\ * Correspondence: f.a.poppelaars@tudelft.nl
}

Received: 15 May 2018; Accepted: 19 June 2018; Published: 22 June 2018

\begin{abstract}
Value creation in a circular economy is based on products being returned after use. In the case of smartphones, most are never returned and tend to be kept in drawers. Smartphone access services (e.g., leasing or upgrade) have been experimented with in the Netherlands but have been largely unsuccessful. This study explores the reasons why consumers rejected these access-based smartphone services and is one of the very few to address this topic. The findings are compared with the case of car access services, which are socially better accepted, to identify potential areas for improvement. The qualitative study consists of in-depth interviews with consumers $(n=18)$ who either adopted and used a smartphone or car access service, or had considered a new smartphone or car but did not choose access-based consumption. The findings of this small-scale study suggest that the main reasons for the rejection of smartphone access services are a lack of awareness, misunderstanding of terms and conditions, and unsatisfactory compensation for their sacrifice of not owning. Smartphone access providers could thus clearly communicate customers' rights and responsibilities, offer an excellent service experience (especially during repair) by taking over the burdens of ownership, and stimulate the societal logic shift from ownership to access.
\end{abstract}

Keywords: consumer behavior; circular economy; behavioral change; consumer acceptance; access model; alternative ownership models

\section{Introduction}

A circular economy (CE) provides a counter weight to our current linear 'take-make-dispose' way of consuming. A CE is "one that is restorative by design, and which aims to keep products, components and materials at their highest utility and value, at all times" [1] (p. 16). To allow resources to loop back into the $\mathrm{CE}$, products need to be returned so that their embedded economic value can be reclaimed through reuse, refurbishment, remanufacturing, harvesting of modules and components, and/or the effective recycling of materials [2,3]. In the existing situation of "sell more/sell faster" [4] (p. 10) where products are owned by their users, the path of unused products depends on the voluntary decision made by the consumer and thus products may or may not be collected at the end-of-use. The concept of accessing instead of owning however offers the certainty of getting back products at the end-of-use [5]. In such an access model [4] (or use-oriented model [6]), the legal ownership of a product remains in the hands of the service provider, who sells the right of use of a physical product for a limited period of time [7] (e.g., through lease or pay-per-use). This model therefore can contribute to the transition towards a CE by ensuring the return of products and their resource management throughout multiple lifetimes.

One of the challenges of access-based consumption is its acceptance in consumer markets [8-10]. Empirical studies on consumer acceptance of access models are scarce [8] and by and large focused on 
what happens before the purchase of such a service. These studies rarely consider the thinking process during the use of the service. Empirical studies on consumer acceptance of access models considering the thinking process before and after purchase are specifically rare for the case of smartphones.

The objectives of this study are to explore (1) why access services for smartphones are currently regularly rejected in the consumer market; (2) what can be learned from access services for cars that are more socially accepted; and (3) what may be recommendations for the development of access services for smartphones to ensure customers durably adopt and accept them in the consumer market. By providing an understanding of factors influencing consumer rejection or acceptance of these access services, (future) smartphone service providers could better inform services' design to increase the adoption and acceptance of their access model, and, as a result, contribute to a transition towards a circular economy.

Insights on consumer adoption and acceptance of smartphone access services are generated based on interviews on consumer experiences of existing services. The factors prompting the consumers to buy into smartphone access models and accept them after use (or not) were explored. We interviewed five adopters who purchased and experienced (a) a smartphone lease service by a Dutch telecom provider or (b) a smartphone upgrade service by a second telecom provider, and four non-adopters who did not purchase these services. The more mature and widely accepted car access services [11] were also examined to explore successful factors for the adoption and acceptance of these access-based services. We interviewed six adopters who purchased and three non-adopters who did not purchase the service of (c) a car lease or (d) a pay-per-use car service. The scope of this study is restricted to for-profit business-to-consumer (B2C) access models (as opposed to non-profit, peer-to-peer or business-to-business models) in Western Europe.

This paper is divided in six sections. In Section 2, a conceptual model of consumer behavior is proposed to identify factors in relevant empirical studies of the consumer acceptance on access-based consumption found in literature. Section 3 reports the methodological aspects of the two series of interviews conducted. The factors along the stages of the conceptual model resulting from these interviews are described in Section 4. In Section 5, the implications of these findings on the three objectives of this study and the findings' limitations are discussed.

\section{Consumer Acceptance of Access Models in Literature}

Access models differ from traditional transactional models in that the relational exchange is ongoing. Where the relation in a transactional model is mostly centered on the transfer of ownership of a product at a single interaction point, in an access model we see a continuing exchange, throughout the service, up until the point that the product is returned to the service provider. In our literature review, we therefore want to distinguish between the consumer decision process until the point of purchase of a service, and the consumer decision process after purchase (during use). The question driving the literature review is to what extent the literature has empirically explored the consumer adoption and acceptance process of access services.

\subsection{Adoption and Acceptance Consumer Behavior Model}

In order to explore adoption and acceptance of access models in literature, a conceptual model of consumer behavior is first presented based on well-established models in literature. Schiffman and Kanuk defined consumer behavior as "the behavior that consumers display in searching for, purchasing, using, evaluating, and disposing of products and services that they expect will satisfy their needs" [12] (p. 3). Then, using this model, knowledge gaps are uncovered in empirical studies on the acceptance of B2C access models.

The Consumer Decision Model [13], also known as the Engel-Blackwell-Miniard (EBM) model, is one of the most widely cited analytical models and allows us to map and explore the relational exchange throughout the length of the service (from need recognition through to divestment). It is an analytical model because it attempts to provide a framework of the key elements that are claimed to explain the 
behavior of consumers. The EBM model is a combination of the input, information process, decision process and variables influencing the decision process. The seven core stages of the decision process of the EBM model are thus used as the backbone of our conceptual model (i.e., (1) need recognition, (2) search, (3) pre-purchase alternative evaluation, (4) purchase, (5) consumption, (6) post-purchase alternative evaluation, and (7) divestment), visualized in the dark grey blocks in Figure 1. These stages are deemed "representative for utilitarian, high involvement products like mobile phones" [14] (p. 745). The assumptions underlying the conceptual model are that the thinking process undergone by consumers is linear and that consumers behave rationally.

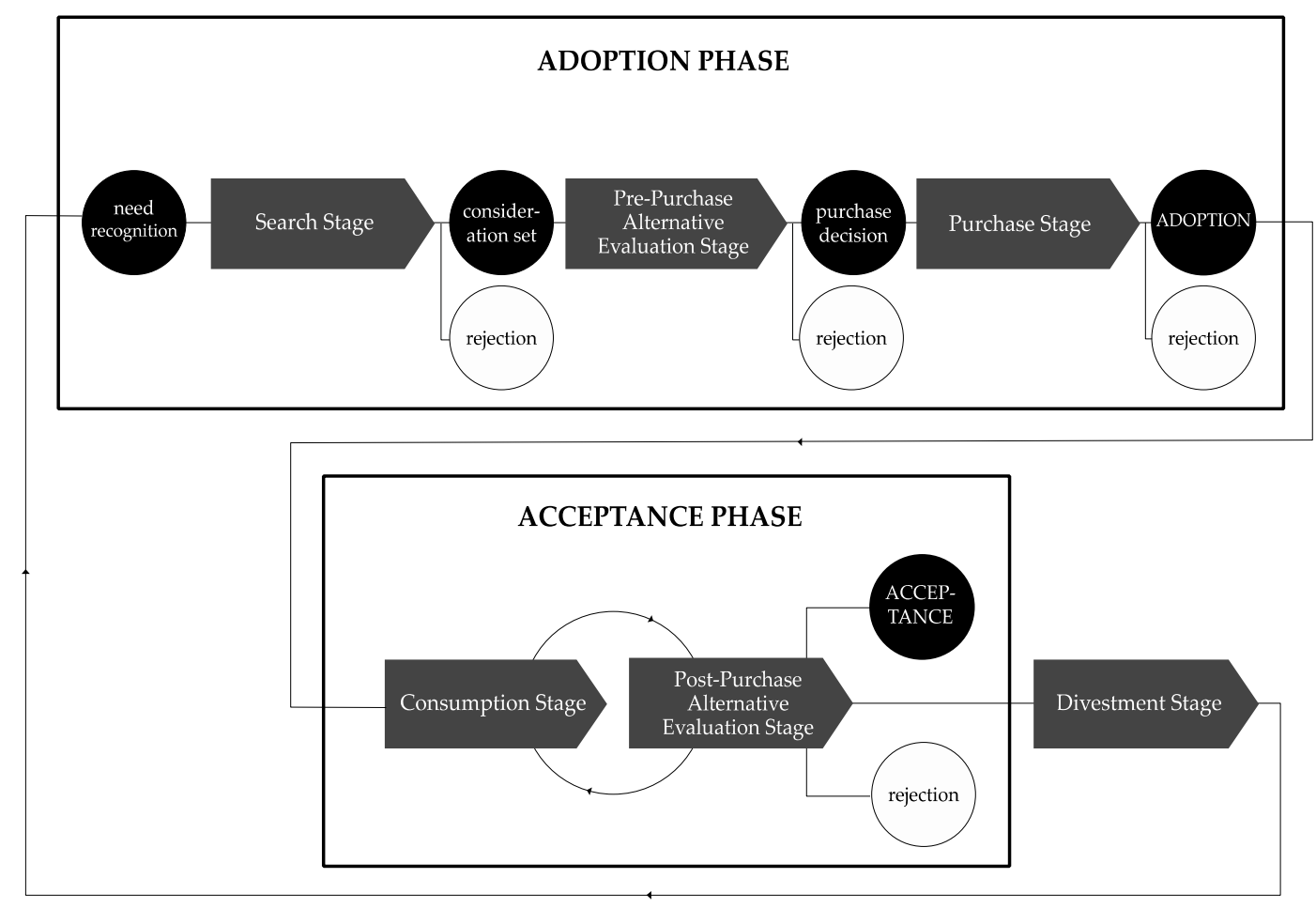

Figure 1. Conceptual model of adoption and acceptance consumer behavior used in this study (adapted from Blackwell et al. [13], Meijkamp [15], and van Weelden et al. [14]). Blocks represent the core stages of the process and circles represent the main outcomes of a stage.

As visualized by black frames in Figure 1, we made a distinction between the adoption phase and the acceptance phase. This distinction was based on Meijkamp's (2000) model distinguishing the adoption decision with respect to car sharing (which according to his categorization includes "informal arrangements", "neighborhood systems", "short-term systems", "subscription systems", "vouchers systems", and "closed systems"), and the service quality perception after usage [15]. For the purpose of this study, we define the term 'adoption' as the psychological action of the consumer of selecting a certain service and making it possible for her/him to use the proposed service. The term 'acceptance' is used to describe the psychological action of credence in a service (including the product at its core). The nuance between adoption and acceptance is that adoption is based on expectations of potential users, and acceptance happens after purchasing the service when the customer actually experiences the service. As a result, the adoption phase goes from the need recognition until the adoption, and the acceptance phase starts after purchasing the service until its divestment. Consumers can reject the service on three different occasions in the model during the adoption phase and once during the acceptance phase. As an analogy, an organ can be transplanted (adopted) but it is not automatically accepted by the receiving body (accepted). 
We furthermore adopted the approach of van Weelden, Mugge, \& Bakker [14] to put emphasis on the specific outcomes of each of the stages in the consumer decision model by adding circles that depict the moments where a consumer can either continue with, or reject, the purchase and consumption process. This addition of the stage outcomes is due to our interest in the experiences of both consumers who actually used the service and consumers who identified the need for a smartphone or car but rejected the access-based service before using it.

\subsection{Literature Review of Empirical Studies on Access-Based Consumption}

Using the Web of Science and Google Scholar databases, our literature review focused on publications covering empirical studies of consumer behavior for B2C access-based consumption in peer-reviewed journal papers, doctoral theses, and master theses published since the year 2000. The initial review used a combination of the following search terms: "access-based consumption", "non-ownership", "product service system", "access", "performance", "collaborative consumption", "empirical", "rent*", "leas", "consumer behavior", and used snowballing to capture additional literature. The selection of publications was made considering their relevance to the scope of our study restricted to for-profit B2C access models and thus excluded for instance publications on non-profit, peer-to-peer, product pooling and sharing, or B2B models.

\subsubsection{Results of Literature Review}

The final overview of 22 studies fitting the scope of the literature review is given in Table 1. The table indicates whether the literature reviewed the adoption or the acceptance phase (with reference to Figure 1) and the kind of product-service studied.

Table 1. Overview of selected empirical studies on the adoption and acceptance of access services within the scope of this study.

\begin{tabular}{ccc}
\hline Publication & Phase Studied & Item at the Core of the Service \\
\hline Armstrong, Niinimaki, Kujala, Karell and Lang (2015) [16] & Adoption & Clothing \\
Bardhi and Eckhardt (2012) [11] & Acceptance & Vipcar) \\
Baumeister (2014) [17] & Adoption & Various \\
Catulli (2012) [18] & Adoption and acceptance & Adoption \\
Catulli, Cook and Potter (2014) [19] & Car (City Car Club and Street Car) \& nursery equipment \\
Nursery equipment \\
Catulli Lindley, Reed, Green, Hyseni and Kiri (2013) [20] & Adoption & Nursery equipment \\
Gullstrand Edbring, Lehner and Mont (2015) [21] & Adoption & Furniture \\
Hanssen and Fjørtoft (2017) [22] & Adoption & Car \\
Kärkkäinen (2013) [23] & Acceptance & Luxury accessories \\
Lamberton and Rose (2013) [24] & Adoption & Clothing \\
Lang and Armstrong (2018) [25] & Adoption & Various \\
Lawson, Gleim, Perren and Hwang (2016) [26] & Adoption & Furniture \\
Lidenhammar (2015) [27] & Adoption & Car \\
Limsupanark, Ming and Pangam (2017) [28] & Adoption & Car \\
Meijkamp (2000) [15] & Adoption & Various \\
Rexfelt and Hiort af Ornäs (2009) [29] & Adoption & Phones \\
Salters (2014) [30] & Adoption & Car \\
Schaefers (2013) [31] & Adoption and acceptance & Car \\
Schaefers, Lawson, Kinney (2015) [32] & Acceptance & Car \\
Sowik, Henkel and Husken (2016) [33] & Acceptance & Car \\
Trocchia and Beatty (2003) [34] & Adoption & Car \\
Trocchia, Beatty and Hill (2006) [35] & Adoption & \\
\hline
\end{tabular}

\subsubsection{Discussion}

The studies considered a variety of products at the core of the service, ranging from transportation to clothing. The majority of the studies identified in the literature address only the adoption phase. They studied the expectations of participants before using the service and did not include the experience of adopters actually using the service (the acceptance phase in Figure 1). It is also clear that, with the exception of Salters (2014) [30], none of the studies address access services for mobile phones in a B2C context.

The majority of the studies furthermore examined hypothetical cases, and not existing services. Therefore, the findings may not be as reliable as when considering the full picture of existing services. 
A content analysis of the selected studies showed common patterns in their findings. These patterns can be categorized into three overarching themes: (A) the importance of trust, (B) unburdening, and $(\mathrm{C})$ habits and necessity.

The first overarching theme concerns the importance of trust. As the results of services are not tangible like the product at its core, the consumers must trust the concept of access-based consumption, the service provider and the community. However, consumers experience a lack of awareness [21] and have difficulty understanding the access models [29,30]. Rexfelt \& Hiort af Ornäs [29] and Catulli et al. [19] show the impact of positive experiences that peers had on the adoption of services. Access models for cars have gained popularity because they increasingly represent an economically savvy, thrifty, and flexible form of consumption, making adopters feel smarter than owners [11,19,20]. In addition, the reputation of the company has been found to play a role in the adoption of access models for cars, nursery equipment, and miscellaneous items, specifically triggered by the power of (high end) brands $[15,18,19,29]$. In contrast, the early rejection of the service can be provoked by the lack of trust in these types of models due to the perceived availability risk [17,24] or lack of trust in the service providers $[16,29,30]$.

The second overarching theme relates to avoiding the 'burdens' linked to ownership. The perceived burdens of ownership (e.g., social, psychological, time, financial, and performance risks of ownership) reduce the willingness of ownership and stimulate the willingness to use of access-based consumption [28,32]. Interestingly, access services were found to foster a sense of community before the adoption phase [22]. The augmented ease, convenience and flexibility are highly appreciated by adopters (found by all studies except [19,20,26,27,32,33]). As highlighted by Edbring et al. [21], Lawson et al. [26] and Salters [30], having a low commitment provides the opportunity to try alternatives and while maintaining the possibility of reversing the decision seems an attractive way to bypass post-purchase dissonance. Conversely, the access agreement conveys limitations, inflexibility and inconvenience [17,19,20,23,30]. Customer have to be careful with the product involved [17,23] (although inconclusive according to [27]). Furthermore, low costs/financial commitment were perceived as beneficial [15,17,19-21,23,26,27,29,32,33]. Note that Armstrong et al. [16] and Lidenhammar [27] found that a one-time fee is preferred.

The third overarching theme touches upon habit and necessity. Engrained habits [15,25,27] and the feeling that these types of models are not meant for the consumer are in the way of the adoption of a specific access model $[15,27,29]$. There is still a desire to own $[15,21,25,26]$. The social stigma of 'not owning' is also a barrier to the adoption of access models [17,18,23]. Moreover, during use, adopters can be disengaged and not attached to the service, product nor service provider $[11,17,33]$. The need for sustainable benefits are mentioned in previous empirical studies $[11,15,17,20,21,30,33]$ (even though car rental services for example are not considered environmental-friendly [22]).

\section{Empirical Study: Materials and Methods}

\subsection{Introduction: Cars and Smartphones}

To better understand why smartphone access services are generally rejected, lessons from more successful access services are needed. Access models for cars are one of the most mature access services on the market [11] and, as seen in the overview in Table 1, most empirical studies on access services focus on cars. Cars and smartphones share a comparable relationship with consumers as they are both considerable expenses, have a utilitarian function in consumers' daily lives and often are considered as extensions of their users' identity. As a result, car consumers are expected to also be involved in an extensive thought-process throughout the adoption and acceptance phases, making the conceptual model in Figure 1 representative for cars too.

\subsection{Data Collection}

Due to the explorative nature of the research, qualitative methods were used, with in-depth semi-structured interviews with non-adopters and adopters of access services for cars and for 
smartphones. Eight interview guides were designed based on Siniscalco \& Auriat (2005) [36] depending on one of the four different services studied (Car2go, BMW, KPN, and Vodafone) and one of the two types of interviewees (a) participants who purchased and used the service (referred to as 'adopters'), or (b) participants who neither purchased nor used the service (referred to as 'non-adopters'). For the non-adopters' interview guides, questions were developed to go through the search, pre-purchase alternative evaluation and purchase stages with the participants (including e.g., prior experience with alternative forms of consumption and the participant's expectations of the service). The first part of the interview guides for adopters followed similar steps. The second part of the adopters' guides covered the purchase, consumption, post-purchase alternative evaluation and potential divestment stages to explore how participants experienced the service (including e.g., benefits and drawbacks at every stage). Within the time constraints of the study, the distribution of the 18 participants was as indicated in Table 2.

Table 2. Distribution of the participants in the study.

\begin{tabular}{cccc}
\hline \multicolumn{2}{c}{ Car } & \multicolumn{2}{c}{ Phone } \\
\hline Non-adopters & Adopters & Non-adopters & Adopters \\
\hline car2go $\mathrm{n}=2$ & car2go $\mathrm{n}=3$ & KPN $\mathrm{n}=2$ & KPN $\mathrm{n}=3$ \\
BMW $\mathrm{n}=1$ & BMW $\mathrm{n}=3$ & Vodafone $\mathrm{n}=2$ & Vodafone $\mathrm{n}=2$ \\
\hline
\end{tabular}

This distribution was made based on the fact that both non-adopters and adopters go through the same decision making process but adopt, accept or reject the service at different points of this process. Eight women and 10 men who were between the age of 24 and 63 participated in the study. The intention was to have a diverse group of potential customers and actual customers to explore various rich experiences.

High prestige brands were selected for each concept to contribute to the reliability of this research. After consideration of well-known access models in the Netherlands, the cases of car2go (a pay-per-use service with electric Smarts in Amsterdam) [37] and BMW Lease (leasing a BMW car through the manufacturer or another service provider) were selected for cars. KPN Lease (lease programs for smartphones by Dutch telecom provider KPN and affiliates in 2012-2014; the telecom provider has a number of affiliate telecom providers were the same lease program was launched. For readability, we will categorize them all under the name of their parent company-KPN) [38] and Vodafone New Phone Every Year (an upgrade program by telecom provider Vodafone preceding Vodafone NEXT and enabling the customer to exchange her/his phone for the newest phone on the market after one year for a monthly fee) [39] were chosen for mobile phones. The participants were found in the authors' network or online on open forums dedicated to the specific services. With the participants' consent, the conversations were recorded when possible and transcribed. Online posts from the participants to the service provider were also used as data.

\subsection{Data Analysis}

The data collected was compiled in codes, defined as "consistent phrases, expressions, or ideas that were common among research participants" [40]. A code name included the stage of the model where the factor occurred and was counted only once per interviewee. The KJ method was used to cluster the identified codes in themes [41]. Neither codes nor themes were pre-defined, as the intention of an explorative study is to uncover themes and patterns unknown in advance. To avoid researcher's biases and test inter-coder reliability, two non-participating researchers coded a transcript and eliminated or altered redundancies and ambiguous themes [40].

238 codes identified in the 18 interviews were grouped into 17 themes along the adoption and acceptance process. The 17 themes identified in the interviews are as listed in Table 3. 
Table 3. Overview of the themes identified in the interviews.

Themes Related to the Importance of Trust

1. Awareness and familiarity with access-based consumption in general or the service in particular (i.e., acquaintance with access-based consumption or the service)

2. Understanding of the service

3. Reliability of and trust in the service (i.e., responsibility for liabilities and consistency of good quality, ability and performance of the service)

4. Relationship with the service provider (i.e., connection and communication between the (potential) customer and the service provider)

5. Image of the service provider (i.e., general impression of the service provider)

\section{Themes Related to Unburdening}

6. Financial aspects of the service (i.e., features of the service relating to finance including price, costs, expenses, payment method and payment scheme)

7. Ease and convenience of the service (i.e., being able to proceed with something without difficulty; e.g., repair process, availability or no need to end the contract)

8. Commitment and flexibility of the service (i.e., level of engagement required for the user to access the offer, and, the adaptability of the service to circumstances \& the ability offered to the user to be flexible in life)

9. Confirmation or excess of the expectations formulated before purchase of the service

10. Value from consumption (i.e., importance, worth, or usefulness the interviewee retrieves from the act of consuming)

\section{Themes Related to Habits and Necessity}

11. Product characteristics at the core of the service (i.e., the car or phone)

12. Affinity and necessity (i.e., affection and the perceived need of the interviewee towards products and alternative services in general)

13. Sustainability (i.e., aspects relating to expected/perceived care in the design of the service when it comes to people, planet, and profit)

14. Similar use of the product than before

15. Product, service or brand attachment

16. Market (i.e., the arena in which commercial dealings are conducted, and existence or not of alternative products or services)

17. Image of access-based consumption (i.e., general impression of alternative ownership models enabling the temporal use of a product)

These themes can be interpreted positively (for instance, the convenience getting something new every year) or negatively (for example, the inconvenience of the unavailability of a car in the proximity).

\section{Results}

\subsection{Results: Adoption Phase}

Figure 2 shows a summary of positive and negative themes that were most mentioned during the various stages of the adoption phase, for both the car access services (indicated with a car symbol) and the mobile phone access services (indicated with a phone symbol).

We will treat the themes identified in the interviews following the overarching themes of importance of trust, unburdening, and habits and necessity found in the results of the empirical studies. Themes mentioned more than twice are summarized in Table 4. 


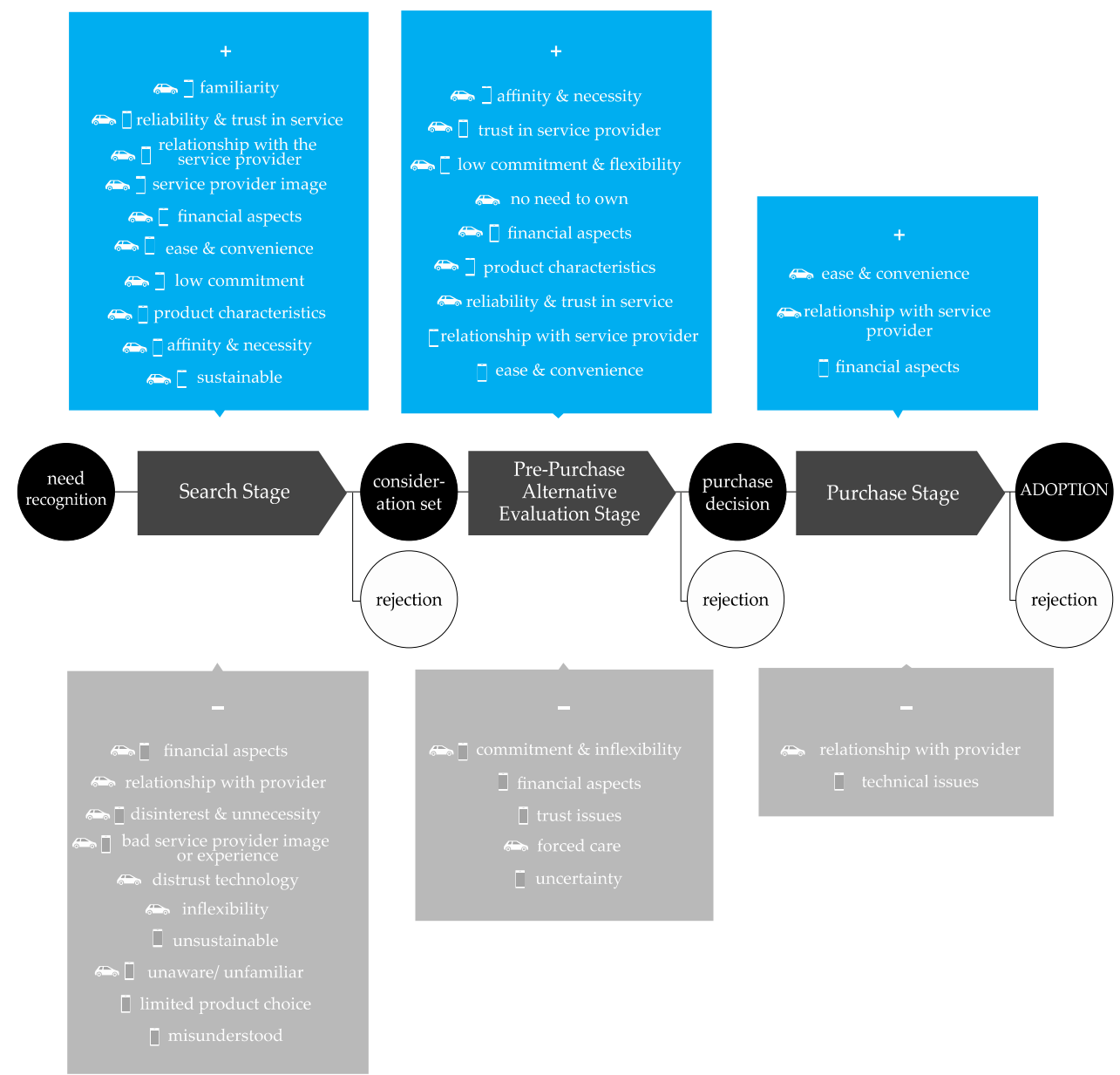

Figure 2. Summary of the themes throughout the stages of the adoption phase for the access services studied for cars (indicated with a car symbol) and phones (indicated with a phone symbol). Positive themes are listed at the top and negative themes are listed at the bottom of the figure.

Table 4. Themes throughout the adoption phase of access models for cars and phones, including their occurrence and example quotes.

\begin{tabular}{|c|c|c|c|c|}
\hline \multirow[b]{2}{*}{ Overarching Themes } & \multirow{2}{*}{$\begin{array}{c}\text { Themes } \\
\text { (+ Positive, }- \text { Negative) }\end{array}$} & \multicolumn{2}{|c|}{ Occurrence } & \multirow[b]{2}{*}{ Quotes } \\
\hline & & $\begin{array}{l}\text { Car } \\
(n=9)\end{array}$ & $\begin{array}{l}\text { Phone } \\
(n=9)\end{array}$ & \\
\hline \multirow{6}{*}{ (A) Importance of trust } & + familiarity & 16 & 22 & $\begin{array}{l}\text { "He said 'oh maybe I can lease a car2go from here'. So he } \\
\text { started the app and then I immediately got information on } \\
\text { how it worked." }\end{array}$ \\
\hline & + reliability and trust in the service & 18 & 13 & "It's a party that I have trusted for years." \\
\hline & + positive image of the service provider & 3 & 10 & "BMW is qualitatively in a higher segment." \\
\hline & - trust issues in the service & 5 & 6 & "Too good to be true." \\
\hline & - unaware/unfamiliar & 4 & 6 & "Never heard of Lease devices." \\
\hline & - (partly) misunderstood & 1 & 4 & "Maybe it takes longer before the phone is yours." \\
\hline \multirow{2}{*}{ (B) Unburdening } & + financial aspects of the service & 7 & 11 & "Two year all inclusive." \\
\hline & - financial aspects of the service & 6 & 1 & $\begin{array}{l}\text { "In return it has its costs, as if you are paying back a loan, } \\
\text { with every month a certain amount of money." }\end{array}$ \\
\hline
\end{tabular}


Table 4. Cont.

\begin{tabular}{|c|c|c|c|c|}
\hline \multirow[b]{2}{*}{ Overarching Themes } & \multirow[b]{2}{*}{$\begin{array}{c}\text { Themes } \\
\text { (+ Positive, }- \text { Negative) }\end{array}$} & \multicolumn{2}{|c|}{ Occurrence } & \multirow[b]{2}{*}{ Quotes } \\
\hline & & $\begin{array}{c}\text { Car } \\
(n=9)\end{array}$ & $\begin{array}{l}\text { Phone } \\
(n=9)\end{array}$ & \\
\hline \multirow{5}{*}{ (C) Habits and necessity } & + product characteristics & 8 & 10 & $\begin{array}{l}\text { "I believe I caved because of the phone that came with it. } \\
\text { I found the Samsung very beautiful, it spoke to me a lot." }\end{array}$ \\
\hline & + necessity & 2 & 3 & $\begin{array}{l}\text { "It's like 'oh I have to have a new phone', 'oh I have to cut } \\
\text { my hair', an intangible need to then have something new." }\end{array}$ \\
\hline & + sustainability & 2 & 2 & "I liked electric driving and not one on fossil fuel." \\
\hline & - lack of necessity or affinity & 3 & 0 & "I'm old-school. I'm in the culture of owning." \\
\hline & - unsustainability & 0 & 2 & "I also find it very wasteful." \\
\hline
\end{tabular}

\subsubsection{Importance of Trust}

Reliability of and trust in the service was mentioned 31 times, by both car and smartphone interviewees, particularly by car adopters (18 times). The relationship and communication with the service provider was often valued by interviewees in the case of phones (11 times vs. 4 for cars). Clarity was prized: "And what I very much liked is that the site Vodafone site was very 'Jip and Janneke' [Dutch expression, meaning very easy to understand] and there wasn't actually a catch because it is clear on the site". However, phone services were also (partly) misunderstood (four times vs. one time for cars).

Several interviewees of the phone services had a positive image of the two telecom providers and their relationship (mentioned 10 times for phones, and 3 for cars), although some also mistrusted the service (e.g., "too good to be true"). Familiarity with access models was specifically relevant to the adoption of phone services ( 22 times). This was mentioned 16 times by car service interviewees. The contrary was also true: unfamiliarity with the service often lead to its early rejection.

\subsubsection{Unburdening}

The perceived ease and convenience of car access-based services is mentioned 12 times, 3 times for phones (e.g., "I expected it to be a kind of counterpart of an insurance for your phone so at the moment something goes wrong with the product or there is damage, you get a repair or a replacement device."). The low commitment threshold of the engagement with the service was considered beneficial in the adoption phase (four times for phones, five times for cars) ("I wanted [the car] very badly, it was insane, so somebody had to tell me that if I made the wrong decision that they could reverse $\mathrm{it}^{\prime \prime}$ ). The financial flexibility of Vodafone New Phone Every Year was appreciated by an interviewee. The financial aspects (i.e., costs and regularity of payments) of the services are found interesting by car and phone interviewees (mentioned 7 times for cars, 11 for phones). Nevertheless, services were at times considered too expensive or the monthly payment construction was not appreciated, especially for cars (six times for cars vs. one time for phones).

\subsubsection{Habits and Necessity}

The product characteristics are found essential to the adoption of the services ( 8 occurrences for cars, 10 for phones): "I believe I caved because of the phone that came with it". New (fun) embedded technology is esteemed for both products. The search for a new solution emerged from a subjective need to have a product for BMW Lease (two times), KPN Lease and Vodafone NPEY (three times in total) and was even compared to the habit of cutting your hair regularly. Also, some interviewees of car services had no interest in a new product or access services whatsoever. Sustainable aspects of the access models were positive factors for both products (mentioned twice). Nevertheless, the unsustainability of services was considered a barrier to the adoption of Vodafone NPEY for two interviewees esteeming the one-year swap opportunity to be wasteful: "you're not going to force yourself to buy a new phone again every year". 


\subsection{Results: Acceptance Phase}

This sub-section only treats the answers of the interviewees who actually acquired the car or phone service. Themes mentioned more than twice are summarized in Table 5. Figure 3 shows a summary of the themes throughout the stages of the customer decision process during the acceptance phase.

Table 5. Themes throughout the acceptance phase including their occurrence and example quotes.

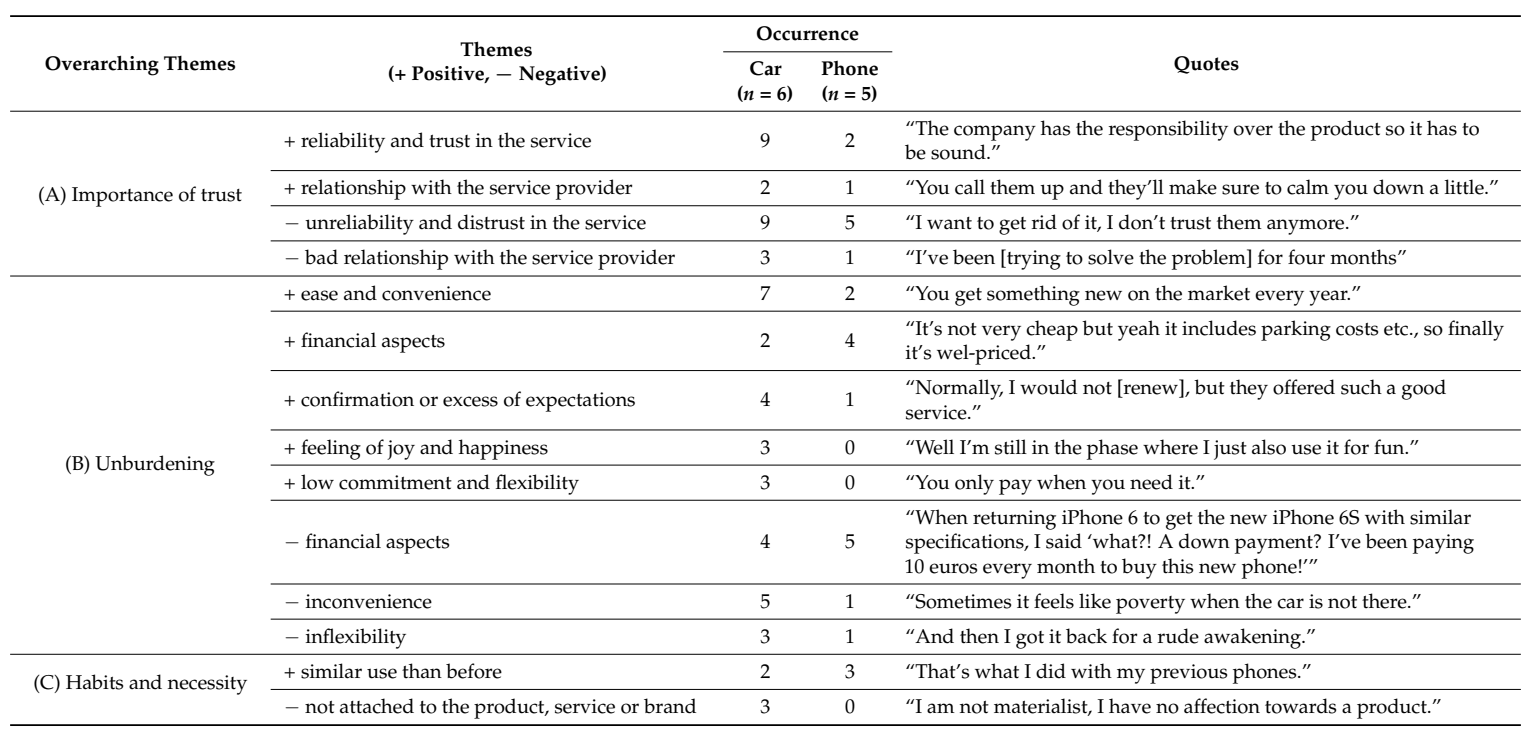

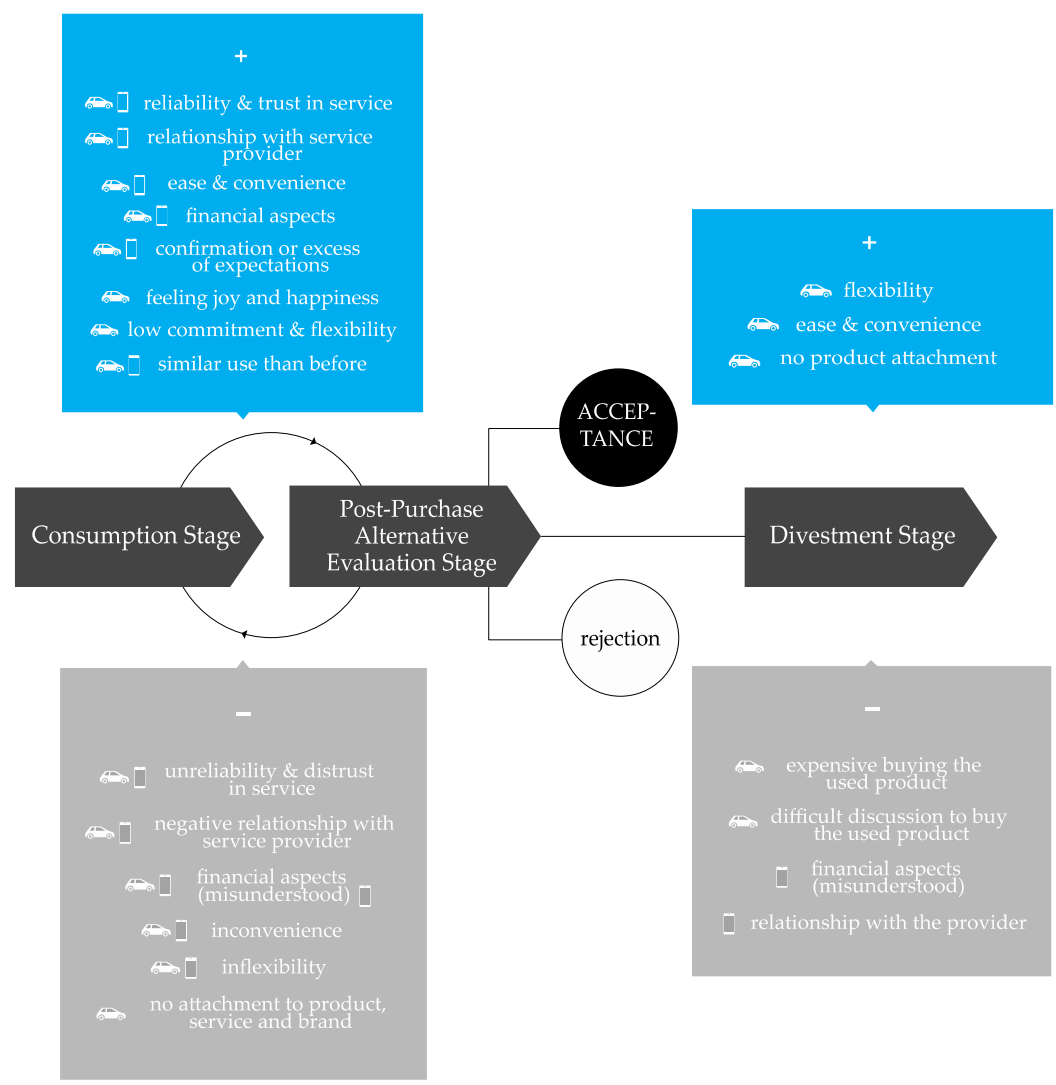

Figure 3. Summary of the themes throughout the stages of the acceptance phase for the access services studied for cars (indicated with a car symbol) and phones (indicated with a phone symbol). Positive themes are listed at the top and negative themes are listed at the bottom of the figure. 


\subsubsection{Importance of Trust}

Reliability and trust in the service was here again fore mostly mentioned by car interviewees (nine occurrences for cars vs. two for phones). However, interviewees for both the car and phone services (nine occurrences for cars, five for phones) experienced drawbacks in use with respect to reliability and trust in the service (all drawbacks mentioned for cars come from car2go respondents). This included adopters experiencing (digital) technical issues, heterogenic service quality, damages, and safety risks; warranty not according to expectations, or service offered later or in a different way than expected. Next to the perceived availability risk, some were troubled with the experienced heterogenic service quality, damages and safety risks, warranty was not according to expectations, or the service was offered later or in a different way than expected. One interviewee was particularly annoyed and finally did not accept the service, saying, "I want to get rid of it, I don't trust them anymore".

Good customer service, guidance throughout the processes of maintenance and repair, and clear communication were esteemed by both car and phone access service adopters (three in total): "you call them up and they'll make sure to calm you down a little. Yes I find it very relaxed." Nevertheless, concerns were raised regarding bad customer service, inconvenient physical contact points, and uncertainty as to how to contact the service provider (three times for cars, one for phones). In the case of KPN Lease, interviewees explained to be expecting a similar service as for car lease (i.e., including repairs and maintenance). As a result, these interviewees felt particularly let down by the service provider when it appeared that repair costs were not included and that the adopter had to pay out of pocket for a needed repair. The lack of homogeneity in the message communicated by the customer service experienced by interviewees did not contribute to making this clearer to adopters on forehand.

\subsubsection{Unburdening}

Expectations on ease and convenience are confirmed for car adopters (mentioned seven times, two times for phones). On the other hand, car pay-per-use adopters were inconvenienced due to product unavailability or the limited working area of car2go (five times). As one interviewee explained, use patterns are in their majority similar across the car2go adopters. Also, a couple of smartphone adopters were very unhappy with the replacement device they received when their product was sent off for repair ("You get a replacement device so old (Android 2.3.6.) on which you can't even log into your Google account.").

Financial aspects were seen as positive during the use (two occurrences for cars, four for phones). The financial aspects were even more often mentioned negatively (four for cars, five for phones). This was for example due to the fact that the expenses were more important in use than expected before purchase. The monthly cost construction was also evaluated as unhandy.

The confirmation or excess of expectations is a strong driver to accept the service (four occurrences for cars, one for phones): "Normally I would not [renew], but they offered such a good service."

A feeling of joy and happiness when using the service was mentioned three times by car service adopters. For one pay-per-use interviewee the line between recreational and functional use was even blurred.

The expected low commitment level and flexibility were indeed experienced but only for car access services (three occurrences). Some interviewees valued the fact that there was no need to end the contract: "you only pay when you need it". However, some car and phone access services adopters (three times for cars, one for phones) found that their freedom was restricted during the use of the service. Several adopters were not even aware of these limitations.

\subsubsection{Habits and Necessity}

When asked how the participants used the product accessed in comparison to a previously owned product, similar use than before (often because of habits) was mentioned two times for cars and three 
for phones: "If you wouldn't have this option, then you could in a matter of speaking resell it then you try to be as careful with as possible", "Yes I always had a cover on my phone".

The lack of attachment to the product, service or brand, was mentioned three times for cars (e.g., "I am not materialist, I have no affection towards a product."). One interviewee even explained he used the product excessively (compared to the use of an owned similar product) as the car was not his.

\section{Discussion}

This study explores the reasons why access-based smartphone services were rejected by interviewed consumers and is one of the very few to address this subject. There are indeed hardly any studies that address access-based consumption in the case of smartphones and most studies on consumer acceptance of access models focus on the adoption phase. This study is unique for its focus on both the adoption and acceptance phase of access-based smartphone services. The findings are compared with car access services, which are better accepted in society, in order to identify potential areas for improvement for smartphone access services.

This explorative study is based on 18 in-depth interviews and is thus impossible to generalize. However, it provides first insights and a few emerging patterns that may be worth exploring further in more detail.

\subsection{Which Factors Led to the Rejection of Smartphone Access Services during the Adoption Phase?}

The adoption phase describes the thinking process that consumers go through before purchasing the service based on their expectations of it only. We have identified five factors in the results of our interviews that most often seem to lead to the rejection of smartphone access services in the adoption phase.

- Lack of awareness and familiarity with smartphone access services. There are not many of these services on the consumer market. In fact, the overall diversity of product categories offered through access-based consumption is limited, with the exception of a few products like cars. Car access services are relatively wide-spread and familiar (car lease is for instance common in a business context) and B2C services are quite visible in the streets (e.g., car2go has recognizable colors and logos on their cars). According to Rexfelt \& Hiort af Ornäs, consumers facing an unfamiliar kind of business offer are tending to "see it in the light of earlier experiences" [29](p.682). We did indeed notice during our interviews that participants compared phone access services to car access services. Participants for instance compared KPN Lease with car lease and expected similar terms and conditions (which was not the case). We also found service providers themselves struggling with the newness of the services. In the case of Vodafone NPEY, participants reported that the service provider did not inform prospective adopters of this access-based option. Unfamiliarity with these services may have a negative influence on consumer understanding, trust, and risk perception. Literature $[19,29]$ confirms the importance of familiarity of the consumer with access services.

- Poor image of the service provider. Simple and to-the-point language, for instance on the website, was appreciated and trusted by some interviewees. However, with others, this raised suspicions ("too good to be true"), especially if the participant had had a prior direct or indirect negative experience with the service provider.

- Financial aspects. In the same fashion as previous literature $[15,17,19-21,23,26,27,29,32,33]$, the financial aspects like costs and financial commitment were often mentioned by our interviewees. Some participants felt the costs were unfairly high because they compared the access services with second-hand products (as it was used by other consumers), considered them a sacrifice of freedom of choice (e.g., limited hardware options), or saw them as an increase of future uncertainty/risks (e.g., unavailability of phone before getting a replacement phone in case of repairs). Particularly for phones, not owning the device at the end of use is a considerable barrier as it is seen as an investment and therefore source of income at the end of consumption. 
- Wanting to own. Similarly to Meijkamp [15], even though the smartphone access service would relieve the burdens of ownership, the perceived need to own new products appeared to be a force of habit. For some participants the perceived need to own new products was very strong, mostly on emotional or financial grounds. Other interviewees, however, argued that the fast new technology cycles were a reason not to own a smartphone and thus a positive motivation for an access model.

- Sustainability concerns. A couple of interviewees wanted the service to make sense environmentally speaking, which according to them was not the case for the upgrade program. On one hand, smartphone adopters have been used to changing their device to a newer one after each end of the telecom provider contract (one or two years) as a habit. On the other hand, the sustainability of a service promoting the consumption of a new smartphone every single year was questioned.

\subsection{Which Factors Led to Rejection of Smartphone Access Services during the Acceptance Phase?}

The acceptance phase was defined as the thinking process that consumers go through after purchasing the service based on their actual experience using it. Three factors were identified in the results of our interviews that frequently seem to stimulate the rejection of smartphone access services in the acceptance phase. The participants show strong adverse reactions when a discrepancy between their expectations and reality occurs.

- Misunderstanding of the access service. Some interviewees (especially loyal clients) tended to intrinsically trust the service provider and thus assumed the service was sound. In some cases, the access-based service was misunderstood, leading to participants having the 'wrong' expectations of the service. For example, a consumer was so excited to get a new device that he rushed into the purchase of the service in the store even though he had just heard about it for the first time and without reading the fine print, assuming that the trusted party had good intentions. Also, as mentioned earlier, interviewees said that they expected a similar service as for car lease (i.e., including repairs and maintenance).

- Stranglehold of the service provider. Accompanying the misunderstanding of the service, some adopters were unpleasantly surprised by the fact that they had to pay a certain amount out of pocket for repairs before the insurance would pay any expenses. What made it even worse, was that they were forced to repair the device as fines were assigned depending on the state of the returned device at the end of use. The lack of freedom and unforeseen additional costs were disliked greatly.

- Perceived subpar service by the service provider. One particular event stood out for all the phone leasers: the break of a device. Drawbacks mentioned by the adopters were the inadequate replacement phone, the rough awakening from being relieved thinking the repair of the lease phone is covered to discovering unanticipated costs, and the recovery process of reprogramming everything back to the original state by the adopter. For two leasers, this resulted in the rejection of the service altogether. Two interviewees felt they were not getting value for their money (i.e., paying for a certain level of service but not receiving it consistently). One interviewee was particularly disappointed in the inconsistent communication from the service provider, especially when a technical error occurred with his contract. Interestingly, one of the three leasers still had a positive experience of the repair process due to the fact that the broken display (along with other unexpected components) were fixed by the repairer, the repair status could be followed online, and the repair service was perceived as easy, skilled, and convenient (i.e., a third-party repairer from KPN came to the leaser's office). 
5.3. How to Increase the Chances of Successful Adoption and Acceptance of Smartphone Access Services Based on the Car Access Services Interviews?

Based on lessons learned from car access services, there seem to be opportunities to increase the chance of success of smartphone access models through:

- Lowering expected risks and uncertainties. Cars can be test-driven before getting the lease contract. Car2go can be trialed, as the registration to the service is non-committal and the member is only charged when actually using the service. These open-ended trials can instigate curiosity and seem to provide a "nothing to lose" feeling, as well as avoiding the possibility of post-purchase dissonance. The car lease service also diminished the consumer uncertainties by, for example, providing an estimate of the residual value of the car at the end-of-use, enabling the prospected leaser to have an overview of the expenses and investment throughout the life of the product.

- Financial aspects. The additional cost premium of the car access services seemed self-explanatory by being all-inclusive and providing an excellent service (linked to the good provider image).

- Providing all-inclusive services. Expectations on ease and convenience are confirmed for car adopters (also mentioned in literature $[11,18,23,31]$ ). The all-inclusive aspect of the services is appreciated as it takes considerable hassles away (e.g., thinking of refilling the parking meter is unnecessary for the pay-per-use service, thinking about maintenance is taken away by regular check-ups by the lease service provider). In the case of cars, the pay-per-use service is considered a luxurious offer if the usual mode of consumption preferred is not/less convenient. If the car is unavailable, it is a momentary disappointment. However, other mobility alternatives exist to go from A to B (e.g., public transportation or bike). The existence of immediate realistic alternatives makes this unavailability less upsetting than the unavailability of a smartphone. These types of alternative products are not possible for smartphones that need to be constantly available. Access services for smartphones should therefore enable the constant access to a technically similar device as the one in current use.

- Carefree value out of consumption. The perceived need to own new products appeared to be a force of habit. When talking about their consumer behavior, the interviewees seemed to often operate from a gut feeling (e.g., "f*cking chic car [ ... ] there are some things you don't need to think about"). This not only happened during the adoption phase, but was also observed during the acceptance phase where car services would instigate happiness and joy through the use of the "fun" electric Smart enabling the access to a special product. Trust in the service provider and service seem essential here. As a result, the consumer behavior process seems rather emotional in contrary to the rational utilitarian decision-making process we were expecting.

- Giving access to well-known brands and exclusive products. Interestingly, the materialistic tendency of one of the interviewees was soothed as the car lease was the only way for him to use a specific car model (mirroring a recommendation from Lang \& Armstrong [16]).

- Increasing the level of maturity and market penetration of smartphone access services. The familiar and mature car access market are used as a reference for smartphone consumers when it comes to access services. The offer of a wider range of phone access services would increase awareness and familiarity with such business propositions.

\subsection{Recommendations to Improve the Adoption and Acceptance of Smartphone Access Services}

Based on the above, we provide a number of recommendations that are worth exploring in more detail when designing access-based services for smartphones to increase the adoption and acceptance of smartphone access services.

- Clear and homogeneous communication throughout the service lifecycle. Smartphone service providers should be aware that consumers tend to compare the service to other access services they are familiar with, and they should adjust their communication to meet these expectations. Marketing and customer services should instigate trust through care and clearly 
yet shortly communicate the rights and responsibilities of the adopters, especially regarding repair, replacement devices, and end-of-use. This communication is particularly essential before the purchase of the service to reduce the chance for the formulation of 'wrong' expectations. Being sustainable may not be the most effective argument to promote access-based services, however an unsustainable service may be a barrier for adoption.

- Excellent service experience to take over the burdens of ownership and retrieve the value in consumption. Access services should be all-inclusive to minimize the perceived risks and uncertainties and have transparent costs. The price premium would be more acceptable if the services would focus on high-end brands of smartphones and provide an excellent experience throughout the stages of the adoption and acceptance phase through exclusivity and uniqueness. The residual value of the product at the end-of-use could be fixed from the start in case the adopter wants to purchase it at the end of the contract or wants to calculate the value of the investment over time. As smartphones are continuously used throughout the day and are sometimes considered as an extension of the self, customers want to be connected without interruptions (contrary to the trip-based use of cars). The 'make or break' moment of the repair experience should therefore be outstandingly designed in order to create a seamless use experience. The irrationality of consumers could also be leveraged by incorporating unique and fun elements (i.e., tangible and intangible) of the access to the product as the central value of consumption. Other negative factors, such as the perceived risk of availability, decreasing durability, or lack of novelty during use, could be balanced out by a dynamically adapted value proposition over time [42] that addresses soft factors such as cost decrease, extra attention, check-ups, software updates, etc. Services could be as flexible as possible to increase the consumers' feeling of being safe and in control. Low commitment without repercussions could be stimulated by offering trial periods to avoid post-purchase dissonance.

- New normal: social and business logic shift. We argue that a business logic shift by companies, as well as a logic shift by society in general, is needed to distance ourselves from ownership to use or value as the central concept of consumption (through access-based consumption) [43]. As a result of the shift, the amount of access services will increase, the uptake will be larger and the chance of familiarity in the family/friend network of non-adopters will thus increase. Also, the invisibility of the use of the service on the accessed product could be remediated through exclusive phone design (e.g., select color or accessory only available for access service adopters). Appropriate marketing and communication are essential to increase the awareness of these services by automatically mentioning this option when adopters are inquiring about new purchase or extension of the contract with the service provider or manufacturer.

\subsection{Limitations and Further Research}

This study has its limitations and opportunities for further research.

It is impossible to avoid that the human nature of the subjects and researchers influences the accuracy of the findings of interviews. The authors are also aware that the nuance between expectations (before acquisition) and perceptions (after acquisition) can be mixed over time in interviewees' head. The interview guides were designed to avoid as much confusion as possible. Nevertheless, we acknowledge the impact on the validity of the results.

The results of this study are based on 18 semi-structured interviews on four different services. Therefore, the findings are not generalizable. This study can serve as a foundation for further research on this subject to realize practical applications.

The diversity of backgrounds and lifestyles of the sample could be expanded in future studies, where segmentation could also be further researched. 'Generation Y' may, for instance, be an important group to leverage, as it would be more inclined to adopt and accept access-based consumption [44].

Privacy issues were not mentioned in our interviews in the case of mobile phones. It may be valuable to research this further as these issues were found in the empirical study on phones by Salters [30]. 
Furthermore, the power of (brand) community was found in literature [11,17,22] but was not reflected in our interviews. Being part of something provides a sense of fulfilment and joy to some adopters (which was lacking in the case of phones), and could be used in the design of the service and interaction with the service provider and other adopters. Also, this study only considered access services provided by telecom providers. It would be valuable to research how the access services provided by smartphone manufacturers are experienced by consumers (e.g., Apple or Samsung Upgrade Program).

The factors found for the adoption and acceptance of smartphone and car access services often coincide. However, the final result of the behavior in general seems biased against smartphone access services. The emotions of our interviewees seem to play an interesting role in this process. We wonder whether-instead of using a linear/rational decision-making approach to consumer behavior (like we did as a starting point of this study) —another approach to consumer behavior (taking these irrational considerations into account) would be enriching for the study of the adoption and acceptance of access-based consumption in further research?

\section{Conclusions}

Mobile phones have been well-spread since the 1990s, however, in the consumer market, the devices have mostly been owned. Access services for smartphones are therefore new to consumers overall, but also new to most service providers. Experiments with access services for smartphones have been attempted in the early 2010s in the Netherlands. This paper explored the first lessons learned on access-based consumption for smartphones based on a small basis of non-adopters and adopters and compared the findings with car access services to identify areas for improvement.

The rejection of smartphone access services during the adoption phase (based on expectations) seem to happen as a result of participants being unaware and unfamiliar with these services, having a poor image of the service provider, feeling they are not compensated properly for their sacrifice, having sustainability concerns, and still remaining in the habit of owning things. The acceptance of smartphone access services (based on experiences) is hindered by the misunderstanding of the access service, the perceived stranglehold of the service provider and the perceived subpar service by the service provider. The car access service interviews demonstrated the need for service providers to prompt trust by lowering expected risks and uncertainties, to take over risks and hassles of ownership with an all-inclusive service, and to leverage consumers' gut feeling (vs rational decision-making). Based on these insights, the adoption and acceptance of access services for smartphones could be improved through clear and homogeneous communication, an excellent experience taking over the hurdles of ownership while keeping enjoyments (especially with carefree repair process), and a social and business logic shift.

Additional research is needed to validate the findings of this exploration on a larger scale, and investigate the aspects of privacy, brand community, and brand/product attachment further.

Does access trump ownership [45]? Not yet. Nevertheless, this paper contributes to the field of access-based consumption by providing insights on why smartphone access services are not as successful as they could potentially be. To enable a transition towards a circular economy, lessons have been drawn from the case of car access services and some recommendations were made to start tipping the scale.

Author Contributions: Conceptualization, F.P.; Data curation, F.P.; Formal analysis, F.P.; Funding acquisition, F.A., C.B., and J.v.E.; Investigation, F.P.; Methodology, F.P.; Project administration, F.P., C.B., and J.v.E.; Resources, F.P., C.B., and J.v.E.; Software, F.P.; Supervision, C.B. and J.v.B.; Validation, F.P., C.B., and J.v.E.; Visualization, F.P.; Writing-original draft, F.P.; Writing - review and editing, F.P., C.B., and J.v.E.

Conflicts of Interest: The authors declare no conflict of interest. The founding sponsors had no role in the design of the study; in the collection, analyses, or interpretation of data; in the writing of the manuscript, or in the decision to publish the results. 


\section{References}

1. Webster, K. The Circular Economy-A Wealth of Flows, 1st ed.; Ellen MacArthur Foundation Publishing: Cowes, UK, 2015.

2. Ellen MacArthur Foundation. Towards the Circular Economy-Economic and Business Rationale for an Accelerated Transition; Ellen MacArthur Foundation Publishing: Cowes, UK, 2013.

3. Balkenende, R.; Bocken, N.; Bakker, C. Design for the Circular Economy. In Routledge Handbook of Sustainable Design; Egenhoefer, R.B., Ed.; Routledge: Abingdon-on-Thames, UK, 2017; pp. 1-19, ISBN 9781138650176.

4. Bakker, C.; den Hollander, M.; van Hinte, E.; Zijlstra, Y. Products That Last; TU Delft: Delft, The Netherlands, 2014.

5. Stahel, W.R. The Performance Economy, 2nd ed.; Palgrave Macmillan: Basingstoke, UK, 2010; ISBN 9780230584662.

6. Tukker, A. Eight types of product-service system: Eight ways to sustainability? Experiences from Suspronet. Bus. Strategy Environ. 2004, 13, 246-260. [CrossRef]

7. Malone, T.W.; Weill, P.; Lai, R.K.; D’Urso, V.T.; Herman, G.; Apel, T.G.; Woerner, S.L. Do Some Business Models Perform Better than Others? MIT Sloan Working Paper; MIT Sloan: Cambridge, MA, USA, 2006.

8. Wallaschkowski, S.; Van Looy, A.; Lohmann, J.; Olschewski, S.; Iba, M.; Kaiser, J.; Hänsch, S. Access vs. ownership: Delving into the facilitators and impediments of access-based consumption form customers' perspective. In Proceedings of the 2nd International Workshop on the Sharing Economy, Paris, France, 28-29 January 2016; pp. 1-24.

9. Annarelli, A.; Battistella, C.; Nonino, F. Product service system: A conceptual framework from a systematic review. J. Clean. Prod. 2016, 139, 1011-1032. [CrossRef]

10. Vezzoli, C.; Ceschin, F.; Diehl, J.C.; Kohtala, C. New design challenges to widely implement "Sustainable Product-Service Systems". J. Clean. Prod. 2015, 97, 1-12. [CrossRef]

11. Bardhi, F.; Eckhardt, G.M. Access-Based Consumption: The Case of Car Sharing. J. Consum. Res. 2012, 39, 881-898. [CrossRef]

12. Schiffman, L.G.; Kanuk, L.L. Consumer Behavior, 9th ed.; Prentice Hall: Upper Saddle River, NJ, USA, 2007.

13. Blackwell, R.; Miniard, P.; Engel, J. Consumer Behavior, 9th ed.; Harcourt College Publishers: San Diego, CA, USA, 2001.

14. Van Weelden, E.; Mugge, R.; Bakker, C. Paving the way towards circular consumption: Exploring consumer acceptance of refurbished mobile phones in the Dutch market. J. Clean. Prod. 2016, 113, 743-754. [CrossRef]

15. Meijkamp, R. Changing Consumer Behaviour Through Eco-Efficient Services-An Empirical Study on Car Sharing in The Netherlands. Ph.D. Thesis, TU Delft, Delft, The Netherlands, 2000.

16. Armstrong, C.M.; Niinimaki, K.; Kujala, S.; Karell, E.; Lang, C. Sustainable product-service systems for clothing: Exploring consumer perceptions of consumption alternatives in Finland. J. Clean. Prod. 2015, 97, 30-39. [CrossRef]

17. Baumeister, C.K. Access versus Ownership: Consumers' Reactions to an Alternative Consumption Mode. SSRN Electron. J. 2014. [CrossRef]

18. Catulli, M. What uncertainty?: Further insight into why consumers might be distrustful of product service systems. J. Manuf. Technol. Manag. 2012, 23, 780-793. [CrossRef]

19. Catulli, M.; Cook, M.; Potter, S. What Value do consumers really expect of Product Service Systems? Reflections on how a different conception of value could facilitate the implementation of PSS in consumer markets. In Proceedings of the 19th International Conference on Towards Sustainable Product Design, Copenhagen, Denmark, 3-4 November 2014; pp. 1-10.

20. Catulli, M.; Lindley, J.K.; Reed, N.B.; Green, A.; Hyseni, H.; Kiri, S. What Is Mine Is Not Yours: Further Insight on What Access-Based Consumption Says about Consumers; Hertfordshire Business School Working Paper; University of Hertfordshire: Hertfordshire, UK, 2013; pp. 1-23.

21. Gullstrand Edbring, E.; Lehner, M.; Mont, O. Exploring consumer attitudes to alternative models of consumption: Motivations and barriers. J. Clean. Prod. 2015. [CrossRef]

22. Hanssen, H.K.V.; Fjørtoft, S. Is Sharing Really (Car)ing? A Quantitative Study on the Perceived Benefits of Access-Based Consumption; BI Norwegian Business School: Oslo, Norway, 2017.

23. Kärkkäinen, H. Renting Luxuries as an Identity Project-A Hermeneutic Approach; Aalto University: Helsinki, Finland, 2013. 
24. Lamberton, C.P.; Rose, R.L. When ours is better than mine? A Framework for Understanding and Altering Participation in Commercial Sharing Systems. J. Mark. 2012, 76, 109-125. [CrossRef]

25. Lang, C.; Joyner Armstrong, C.M. Collaborative consumption: The influence of fashion leadership, need for uniqueness, and materialism on female consumers' adoption of clothing renting and swapping. Sustain. Prod. Consum. 2018, 13, 37-47. [CrossRef]

26. Lawson, S.J.; Gleim, M.R.; Perren, R.; Hwang, J. Freedom from ownership: An exploration of access-based consumption. J. Bus. Res. 2016, 69, 2615-2623. [CrossRef]

27. Lidenhammar, R. Hopping on the Service Bandwagon towards a Circular Economy Consumer Acceptance of Product-Service Systems for Home Furniture. Master's Thesis, Lund University, Lund, Sweden, 2015.

28. Limsupanark, J.; Ming, X.; Pangam, P. Study on the Influence of Customers' Risk Perception on the Use of Leasing Services Based on the Burden of Ownership. Int. Bus. Res. 2017, 10, 147. [CrossRef]

29. Roy, R.; Shehab, E.; Tiwari, A.; Rexfelt, O.; Hiort, V. Consumer acceptance of product-service systems. J. Manuf. Technol. Manag. 2009, 20, 674-699. [CrossRef]

30. Salters, I. From Consumers to Users and Contributors. Master's Thesis, Delft University of Technology, Delft, The Netherlands, 2014.

31. Schaefers, T. Exploring carsharing usage motives: A hierarchical means-end chain analysis. Transp. Res. A Policy Pract. 2013, 47, 69-77. [CrossRef]

32. Schaefers, T.; Lawson, S.J.; Kukar-Kinney, M. How the burdens of ownership promote consumer usage of access-based services. Mark. Lett. 2016, 27, 569-577. [CrossRef]

33. Sowik, N.; Henkel, S.; Husken, K. The Mediated Effect of Psychological Ownership on Loyalty in Access-Based Consumption: The Case of Carsharing. In Proceedings of the 26th Annual RESER Conference, Naples, Italy, 8-19 September 2016; pp. 1112-1129.

34. Trocchia, P.J.; Beatty, S.E. An empirical examination of automobile lease vs finance motivational processes. J. Consum. Mark. 2003, 20, 28-43. [CrossRef]

35. Trocchia, P.J.; Beatty, S.E.; Hill, W.W. A typology of motor vehicle consumers using motives for leasing verus financing. J. Consum. Behav. 2006, 5, 304-316. [CrossRef]

36. Siniscalco, M.T.; Auriat, N. Questionnaire design. In Quantitative Research Methods in Educational Planning; Ross, K.N., Ed.; UNESCO: Paris, France, 2005; pp. 1-85.

37. Car2go Nederland B.V. car2go Amsterdam. Available online: https://www.car2go.com/NL/en/amsterdam (accessed on 12 May 2018).

38. Bencom, B.V. Toestellease. Available online: https://www.bellen.com/mobiel/toestellease (accessed on 12 May 2018).

39. Vodafone Vodafone New Phone Every Year. Available online: https://www.vodafone.nl/shop/mobiel/ abonnement/extra-opties/new-phone-every-year.shtml (accessed on 12 May 2018).

40. Turner, D.W. Qualitative Interview Design: A Practical Guide for Novice Investigators. Qual. Rep. 2010, 15, 754-760.

41. Scupin, R. The KJ method: A technique for analyzing data derived from Japanese ethnology. Hum. Organ. 1997, 56, 233-237. [CrossRef]

42. Den Hollander, M. Managing Obsolescence: Extending Product Lifetimes in a Circular Economy. Ph.D. Thesis, TU Delft, Delft, The Netherlands, 2018.

43. Poppelaars, F.A.; Bakker, C.A.; Engelen, J.M.L. Van The (IL)Logic of Ownership-Exploring Alternative Commercial Offers for Mobile Devices. In Proceedings of the Electronics Goes Green 2016+, Berlin, Germany, 7-9 September 2016; pp. 1-8.

44. Godelnik, R. Millennials and the sharing economy: Lessons from a "buy nothing new, share everything month" project. Environ. Innov. Soc. Transit. 2017, 23, 40-52. [CrossRef]

45. Gansky, L. The Mesh: Why the Future of Business Is Sharing; Penguin Group: New York, NY, USA, 2010.

(C) 2018 by the authors. Licensee MDPI, Basel, Switzerland. This article is an open access article distributed under the terms and conditions of the Creative Commons Attribution (CC BY) license (http:/ / creativecommons.org/licenses/by/4.0/). 